\title{
SPATIOTEMPORAL ANALYSIS FOR WILDLIFE-VEHICLE-COLLISIONS BASED ON ACCIDENT STATISTICS OF THE COUNTY STRAUBING-BOGEN IN LOWER BAVARIA
}

\author{
R. Pagany*, W. Dorner \\ Technology Campus Freyung - DIT, Deggendorf Institute of Technology, Germany \\ *raphaela.pagany@th-deg.de,wolfgang.dorner@th-deg.de
}

Commission VIII, WG VIII/7

KEY WORDS: wildlife-vehicle-collisions, dynamic risk management, remote sensing data, land use, vegetation periods

\begin{abstract}
:
During the last years the numbers of wildlife-vehicle-collisions (WVC) in Bavaria increased considerably. Despite the statistical registration of WVC and preventive measures at areas of risk along the roads, the number of such accidents could not be contained. Using geospatial analysis on WVC data of the last five years for county Straubing-Bogen, Bavaria, a small-scale methodology was found to analyse the risk of WVC along the roads in the investigated area. Various indicators were examined, which may be related to WVC. The risk depends on the time of the day and year which shows correlations in turn to the traffic density and wildlife population. Additionally the location of the collision depends on the species and on different environmental parameters. Accidents seem to correlate with the land use left and right of the street. Land use data and current vegetation were derived from remote sensing data, providing information of the general land use, also considering the vegetation period. For this a number of hot spots was selected to identify potential dependencies between land use, vegetation and season. First results from these hotspots show, that WVCs do not only depend on land use, but may show a correlation with the vegetation period. With regard to agriculture and seasonal as well as annual changes this indicates that warnings will fail due to their static character in contrast to the dynamic situation of land use and resulting risk for WVCs. This shows that there is a demand for remote sensing data with a high spatial and temporal resolution as well as a methodology to derive WVC warnings considering land use and vegetation. With remote sensing data, it could become possible to classify land use and calculate risk levels for WVC. Additional parameters, derived from remote sensed data that could be considered are relief and crops as well as other parameters such as ponds, natural and infrastructural barriers that could be related to animal behaviour and should be considered by future research.
\end{abstract}

\section{INTRODUCTION}

Wildlife-vehicle-collisions (WVC) are an issue for road safety and considerably contribute to street accidents and costs (e.g. Morelle, Lehaire, \& Lejeune, 2013, p. 53). Research projects from Europe and North America (e.g. Hartwig, 1993; Hindelang, Premo, Rogers, \& Premo, 1999; Hubbard, Danielson, \& Schmitz, 2000; Morelle et al., 2013) show that spatial and temporal analysis can help to identify patterns and identify areas at risk. Studies with an application oriented background focus on classical preventive and protection measures such as fences or reflectors (e.g. Diaz-Varela, Vazquez-Gonzalez, Marey-Pérez, \& Álvarez-López, 2011; Krisp \& Durot, 2007; Putmam, 1997). This draws the attention of authors also on static accident patterns with an annual reoccurrence. But established prevention and protection measures such as fences, warning signs, speed limits or reflectors are questioned due to costs and effectiveness (Putmam, 1997, p. 43).

Hence, two critical issues arise: First, because of the regional nature of studies a direct transfer of results to other regions is disputable. Traffic conditions, driving regulations, road construction principles, habitat conditions as well as population numbers and species can vary from region to region and continent to continent. Second, the static nature of established warning and protection measures means that in a lot of studies land use, land use patterns and the dynamics of land use over the year and resulting seasonal effects, as very dynamic parameters, are not considered.

This paper wants to address three research questions:
First, can established spatio-temporal analysis approaches be applied to the situation in Bavaria, especially rural areas with a scattered settlement structure? Second, are there indicators that land use should be taken into account as a relevant parameter in analysing WVC? Third, are there possibilities for a practical approach considering especially the availability of data, to also include land use and land use patterns to explain WVC?

\section{LITERATURE DISCUSSION}

\subsection{Overview}

Using Geo Information Systems (GIS) for WVC management has a long tradition. Already in 1999 Hindelang, Premo, Rogers, \& Premo (1999) developed a Decision Support System using GIS methodologies to identify focus areas and high risk areas. Since then several studies applied GIS based methodologies, temporal statistical as well as mixed approaches (e.g. Diaz-Varela et al., 2011; Gunson, Clevenger, Ford, Bissonette, \& Hardy, 2009; Hindelang et al., 1999; Hubbard et al., 2000)

Reasons for an increasing interest in WVC can be seen in changes of numbers and costs of WVC. Morelle et al. (2013, p. 62) points out the significant increase in WVC of over $100 \%$ between 2003 and 2010 and high costs (p. 54) for a study in Belgium. But not only rural areas are considered to be relevant, also urban areas are in the scientific focus and show increasing 
numbers of WVC (Found \& Boyce, 2011; Nielsen, Anderson, \& Grund, 2003). Different reasons can be identified. "The increase in the number of car-killed red deer was mainly an effect of increasing population size" (Mysterud, 2004, p. 203), but also growing traffic is seen as an influencing factor.

\subsection{Temporal Effects}

A strong dependency seems to exist between time and WVC. "In consequence most such road crossings will occur at night (with peaks at dawn and dusk as animals move to and away from feeding areas away from cover [...]), except in wellwooded areas where crossings may occur at any time of day or night." (Putmam, 1997, p. 45). This is confirmed by Morelle et al. (2013, p. 53) identifying a concentration of accidents at night time with peaks at dusk and dawn as well as Hartwig (1993, p. 27) for North-Rhine Westphalia.

Hindelang, Premo, Rogers, \& Premo (1999) sees correlations between these day-night changes due to animals' activities and changing traffic density over day. For seasonal variations this is supported by Morelle et al. (2013, p. 53): "Monthly distribution revealed the role of breeding, dispersal and hunting in shaping temporal patterns of accidents." They see especially hunting period as a main driving force for the concentration of WVC during some periods of the year (p. 65)

\subsection{Spatial patterns}

Depending on species and season also different spatial patterns seem to be possible. "For all the species but roe deer, distribution of roadkills followed the same patterns, with significant clustering at scale ranging from one to more than fifty kilometres (Figure 9). While wild boar and red fox accidents become randomly distributed at large scale $(>60 \mathrm{~km})$, red and roe deer accidents, quickly switch from a clustered to a dispersed distribution. For roe deer, clustering of accidents occurred until a scale of twenty kilometres and at scale higher than forty kilometres distribution becomes dispersed" (Morelle et al., 2013, p. 63)

Landcover along the street may influence the occurence of deer and hence the risk for accidents. "Recent findings are that deer habitat needs are met in areas with abundant grasslands and orchards with nearby hardwoods (especially oaks) for refugia." (Hindelang et al., 1999, p. 1).

Dussault, Poulin, Courtois, \& Ouellet (2006) identified indicators for correlations between landscape structures (valleys, pools) and accidents. While Putmam (1997, p. 53) also provides hints how interannual changes may influence WVCs: "By the same token, cover planted near to road fences will encourage deer usage and increase the risk of road crossings; ironically, the current practice of planting trees on motorways cuttings and verges, while effective in landscaping terms, actually encourages deer to the road edges and increases the risks of deer-related accidents."

\section{METHODOLOGY}

Research is structured in three different parts following the research questions. First to test the applicability of models developed in other regions a GIS and statistical approach will be followed to analyse the influence of day time, season, species and road type on spatial and temporal distribution of WVC. The approach to analyse spatial parameters and visualize data is based on ESRI ARCGIS and QGIS.

Second the relevance of land use as an explanatory factor will be tested for selected hot spots based on a visual analysis of the development of vegetation over time to identify seasonal as well as annual changes. For this a set of Landsat 7 Images was preprocessed for Band $1-3$ compensating SLS-Off by the gap masks provided in USGS data sets and overlaid with WVC data. A qualitative analysis will be performed by comparing land use as well as land use patterns with WVC to identify patterns that could be in a next step be linked to animal behaviour and as a parameter taken into account for newly developed models.

Based on this approach will be tested weather remote sensed data could be used to identify correlations between WVC and land use.

Relief, structural and infrastructural elements at and alongside streets have not directly been analysed and taken into account as relevant parameters for modelling and explaining WVCs. Putmam (1997, p. 54) indicates, based on earlier studies, that removing steep road sides would increase visibility and, hence, could contribute to a reduction of WVCs. The impact of these structures on animal behaviour are not addressed.

But also the size of roads influences movement patterns, due to traffic density, but also because major roads seem to define home ranges (Putmam, 1997, p. 46). Also other aspects with regard to drivers and accidents are seen while age, gender and experience seem to influence the probability of WVCs (Hartwig, 1993, p. 26). The purpose of such studies needs to be discussed. Putmam (1997, p. 43) points out, that "the relative efficacy or cost-effectiveness of different control options is poorly understood."

\section{CASE STUDY}

As a case study area the Bavarian county Straubing-Bogen was chosen. The county is a rural area in the south east of Bavaria. Landscape is characterized by the Bavarian Forest, a mountainous rural area predominantly used for forestry in the northern part of the county, the Danube River and river valley in the center flowing almost from west to east and the flat and fertile area of the Gäuboden predominantly used for agriculture (see e.g. Figure 2). The city of Straubing is almost located in the center of gravity of the county.

\section{RESULTS}

For the county of Straubing Bogen (SR) a data set was available, including all WVCs reported to local police stations either by the driver or by hunters responsible for the hunting area the accident happened in. These data sets do not include accidents that were never reported (hit-and-run) and detected or handled due to communication between the driver and the local responsible hunter, excluding local police. There are no official numbers available to identify the resulting difference between reported accidents to police and the total number of accidents.

For SR a total number of 5,194 was reported (Table 1) for the period 2010 - 2014. Numbers of WVC between 2010 and the other years differ significantly, because in the second half of 2010 the digital register for WVC was invented, so 2010 covers only the second half of the year. This needs to be considered while analysing seasonal effects. 
Table 1 Annually reported WVCs for the district of Straubing-Bogen

\begin{tabular}{|rr|}
\hline Year & Number of WVCs \\
\hline 2010 & 476 \\
2011 & 1,015 \\
2012 & 1,191 \\
2013 & 1,131 \\
2014 & 1,381 \\
Total & 5,194 \\
\hline
\end{tabular}

WVC are spread all over the county (Figure 1) showing differences between the individual regions with regard to total number, density and species affected. Accidents at the highway (Bundesautobahn A3) are mainly bird of prey, rabbit and fix due to protective fences. Dear and rabbit is predominant in the agricultural and flatter areas of the south. Boar is mainly located in the hilly forests in the north.

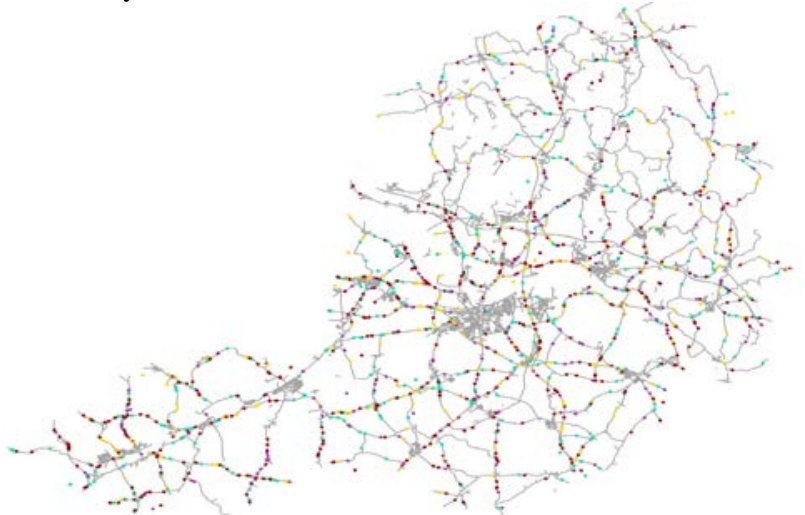

Figure 1. Spatial distribution of WVC in the county Straubing-Bogen

Spatial distribution (Kernel Density) indicates some hot spots for WVC (Figure 2).

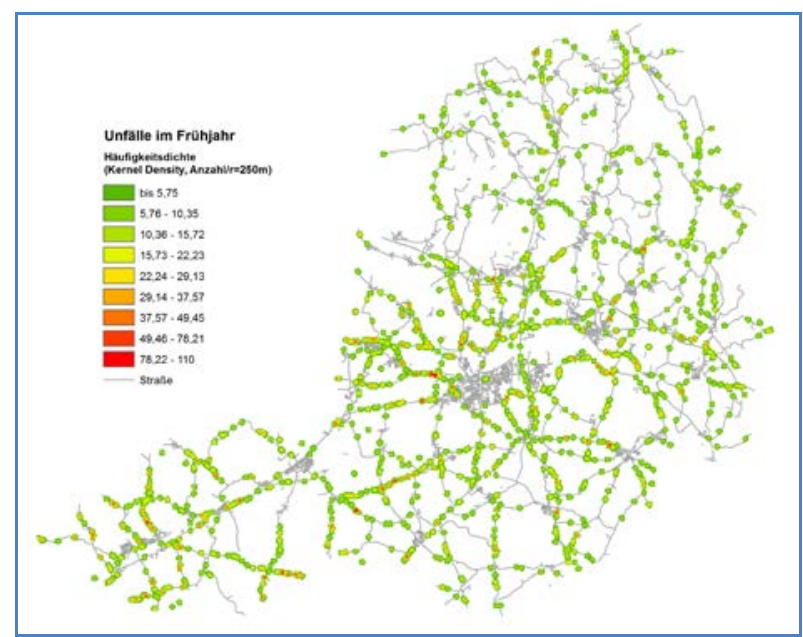

Figure 2 Kernel density of WVC in spring for 250 sections of the road network

The spatial distribution of WVC depends on species and season as shown for a selected sub-region in Figure 3. The pattern during spring, summer and autumn is mainly scattered, while during winter season there is a concentration in forest areas. Also affected species vary, while rabbit (Hase) and wild boars (Schwarzwild) mainly contribute to accidents in spring and summer, the majority of accidents is caused by roe, red and fallow deer.

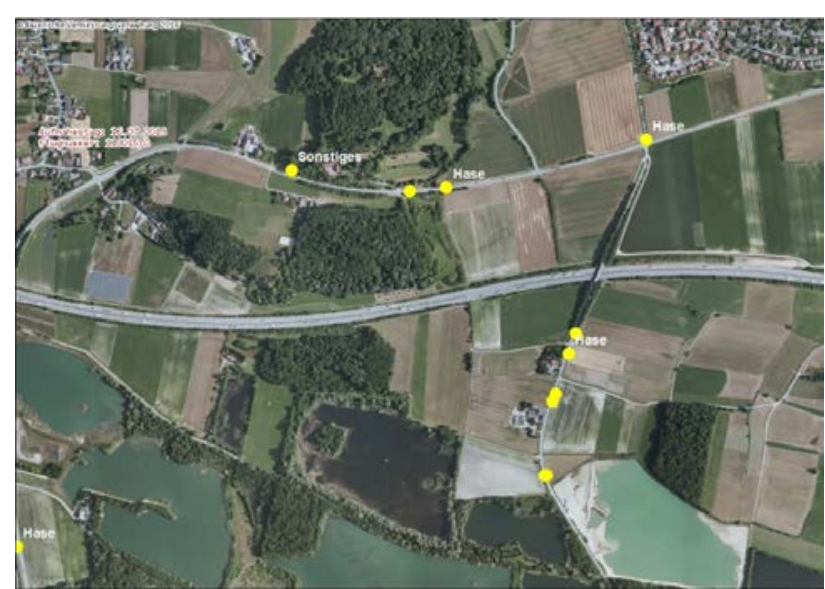

$$
\text { a) Spring }
$$

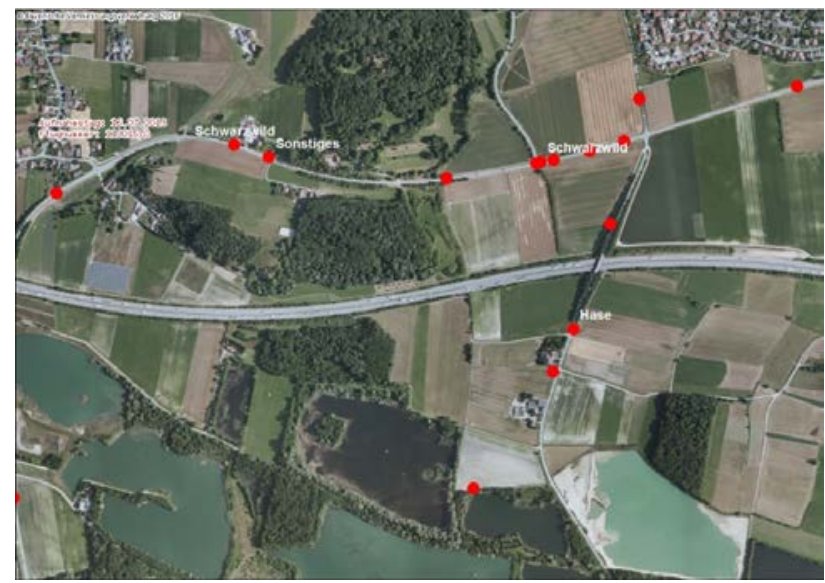

b) Summer

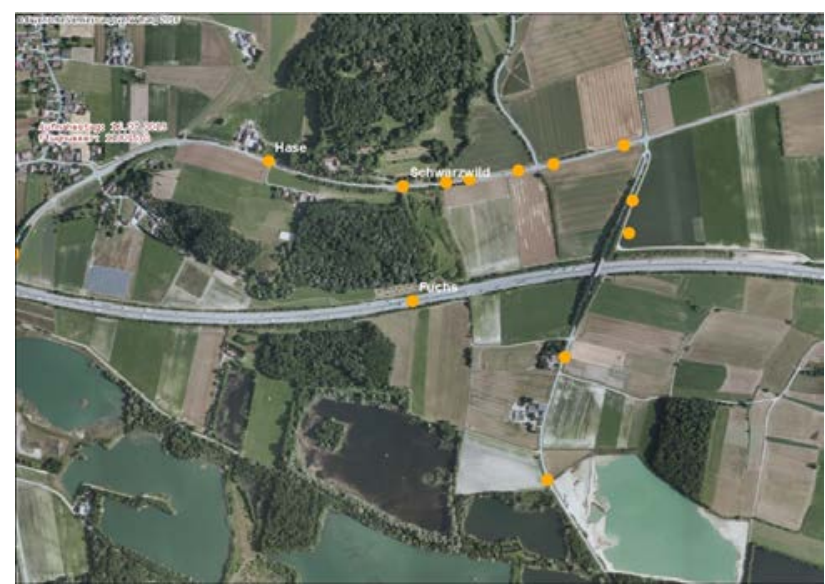

c) Autumn 


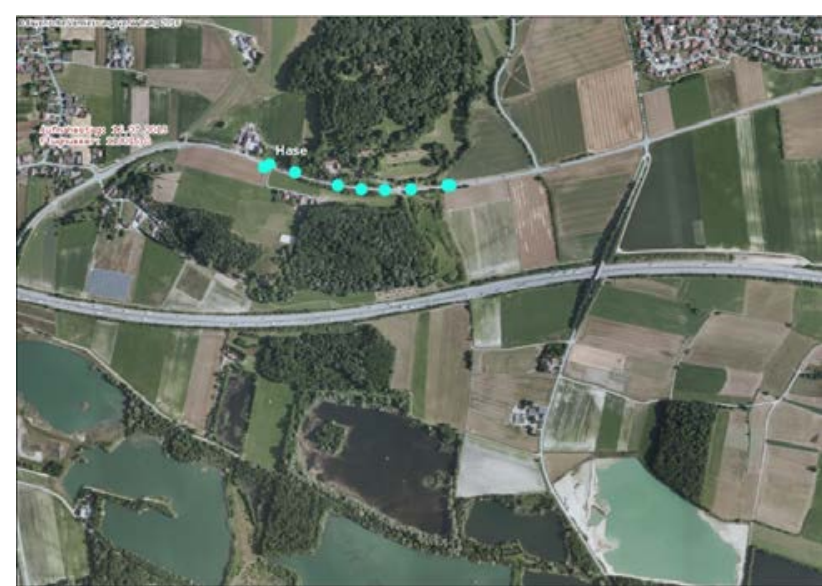

\section{d) Winter}

Figure 3 Spatial distribution of WVC comparing the seasons for the period 2010 - 2014

The temporal distribution (season and day time) of WVC depends strongly on the species. Figure 4 shows exemplarily the day time and seasonal distribution for bird of prey and wild boar as the species with the most significant temporal concentration of WVCs while this general pattern can also be transferred to other species.

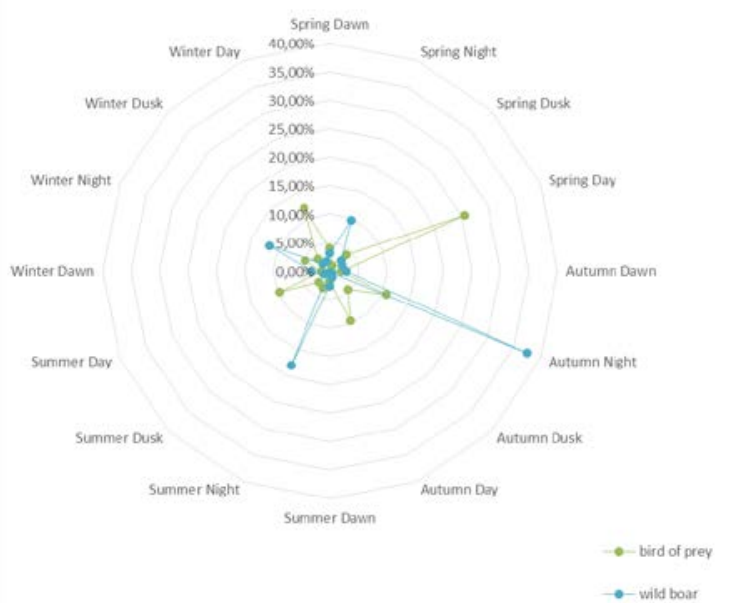

Figure 4 Seasonal and day time distribution of WVC for bird of prey and wild boar

Having a closer look at the distribution of WVC with regard to land use pattern, in the given project region land use and vegetation is strongly influenced by agriculture, resulting in not only seasonal differences, but also significant annual changes due to crop rotation. An analysis of three Landsat scenes for the years 2011, day 234 (Figure 5), 2012, day 214 (Figure 6) and 2013, day 207 (Figure 9) show the same area during the main vegetation period of most farm cultures in late July and early August.

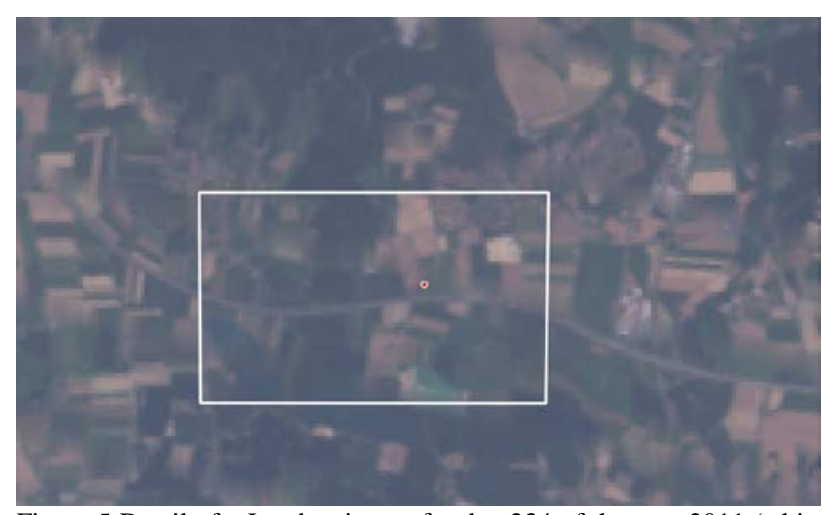

Figure 5 Detail of a Landsat image for day 234 of the year 2011 (white rectangle indicates borders of the aerial image from Figure 3)

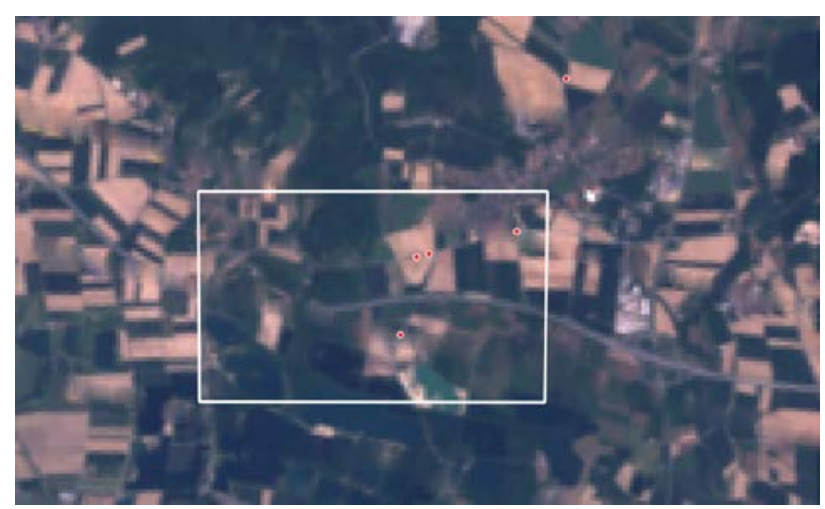

Figure 6 Detail of a Landsat image for day 214 year 2012 (white rectangle indicates borders of the aerial image from Figure 3)

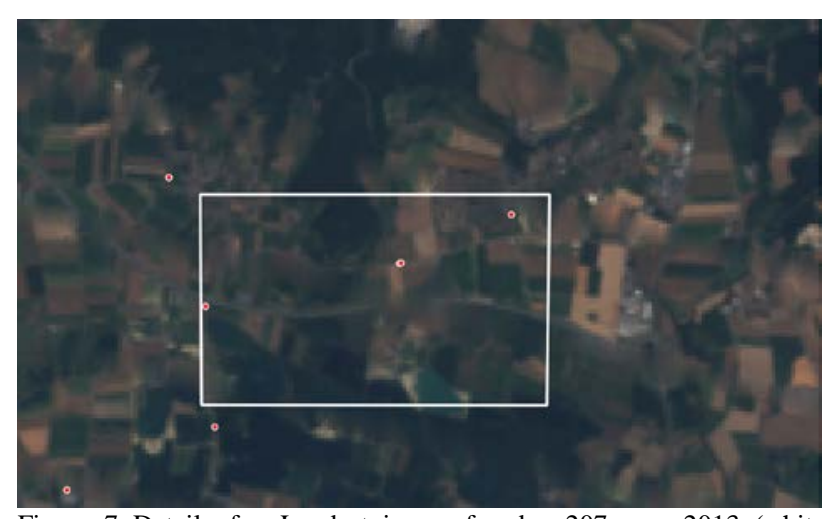

Figure 7 Detail of a Landsat image for day 207 year 2013 (white rectangle indicates borders of the aerial image from Figure 3)

In one year (2013) the distribution of WVC is wide spread, which may be related to vegetation periods and individual crops or plants (Figure 9, Figure 10, Figure 11). The majority of accidents occur during spring, summer and autumn period in the agricultural areas, while winter accidents are located around forests. 


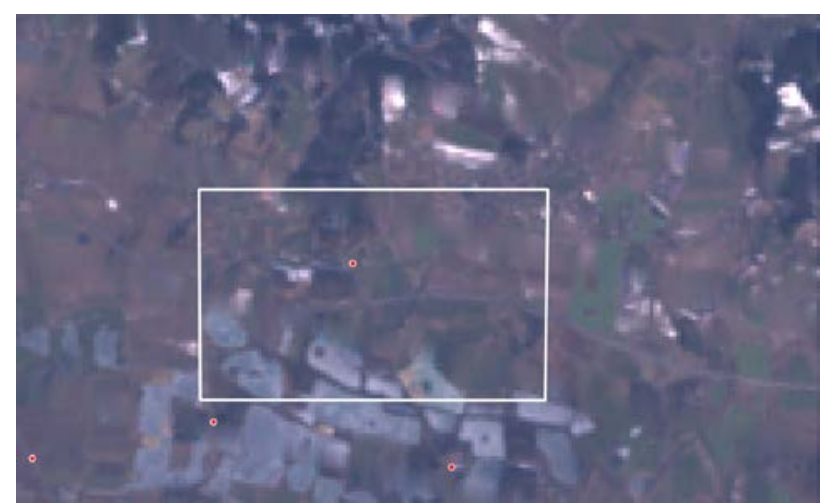

Figure 8 Detail of a Landsat image for day 063 year 2013 (white rectangle indicates borders of the aerial image from Figure 3)

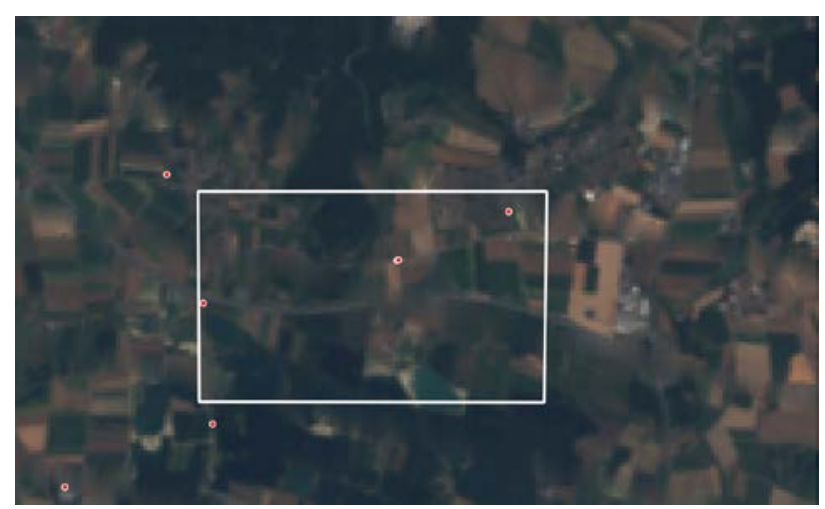

Figure 9 Detail of a Landsat image for day 207 year 2013 (white rectangle indicates borders of the aerial image from Figure 3)

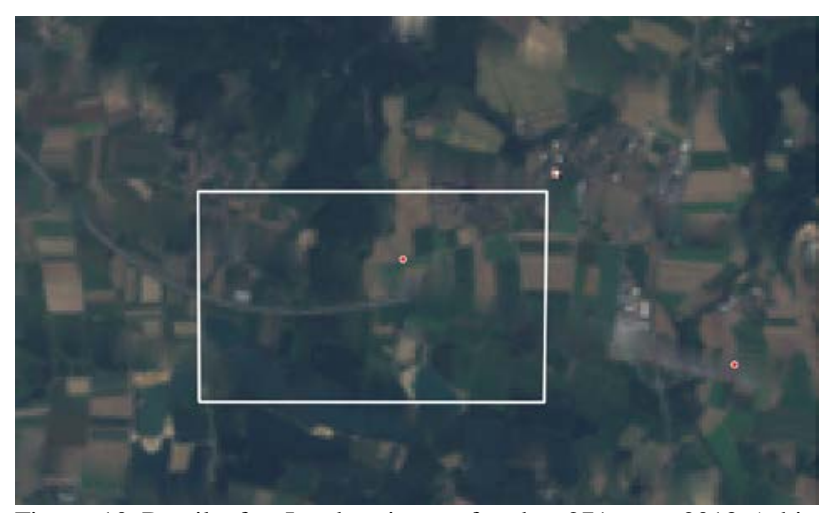

Figure 10 Detail of a Landsat image for day 271 year 2013 (white rectangle indicates borders of the aerial image from Figure 3)

\section{DISCUSSION}

Data was made available by local police authorities and does not cover the total number of accidents, but only those accidents reported to the local police. While the number of total accidents is not available, it is difficult to discuss the gap. It can only be assumed that these missing accidents are randomly distributed, so they would follow generally the here identified pattern. One factor could challenge this assumption, because under German law also a local responsible hunter could take up the accident and provide relevant data and statements for insurance companies without an involvement of the police. Personal relations in rural areas could be a reason why the spatial distribution of reported in contrast to unreported accidents could differ. But this may only be relevant to explain differences between rural and urban areas, but should not influence spatial distribution in rural areas and especially not temporal patterns.

The results show quite well, that research findings from other projects and especially other regions can be transferred to Germany and need to be adopted with regard to underlying basic data and geodata, but can be applied using the same assumptions taking into account spatial and temporal patterns. Temporal approaches such as daytime and seasonal influences can be used to explain changes in risk for WVC.

But there are still gaps in and between approaches explaining accident patterns. The situation presented in Figure 3 can only partially be explained by applying current modelling approaches. The analysis of accidents based on seasons indicate, that there is especially during winter season a strong concentration of accidents in forest areas. But this idea combines seasonal analysis with land use pattern or the spatial distribution of land use to explain WVC, a hypothesis not validated yet. To apply only spatial patterns of land use would fall short and is not able to explain the strong variation of WVC for the rest of the year, where neither land use pattern nor season or a combination of both indicates to be a suitable approach.

A further analysis of land use on basis of Landsat Satellite Imagery shows a significant change in vegetation coverage over time. Taking different scenes for one year and different vegetation periods indicates that land coverage could have an influence on WVC. These changes occur over a one year vegetation period. In rural areas also annual changes in land use should be considered.

The analysis of Landsat data for different years and seasons gives indications that spatial variability may depend on land use and the seasonal situation of vegetation. This analysis still lacks the integration of weather data that also could be an explanatory variable, influencing animal behaviour and drivers reaction and is not based on a strong quantitative basis.

There are two hypothesis that could be derived and need to be addressed by future research:

1. Land use and its spatial distribution influences animal behaviour resulting in changed spatial movement patterns influencing the local probability of WVC

2. Changes in land use influence the visibility of wild animals for car drivers resulting in a changing WVC risk over the year

Land use data, relevant to model seasonal as well as annual changes, is not available for purposes of WVC modelling. Public geospatial data does not provide sufficient discretized resolution with regard to types of land use and does not allow to identify annual changes in land use e.g. in agriculture. Data from agricultural statistics is only available in a low spatial resolution. Satellite data could be used, if reference data could be provided to achieve an adequate parametrisation.

\section{CONCLUSION}

The project focused on the applicability of spatio-temporal models to identify and explain hot spots of WVC, looked at the potential relevance of land use and land use pattern and discussed approaches to model land use and WVC in a spatiotemporal context.

For this GIS models together with statistical analysis were applied and confirm the relevance of several in the scientific literature emphasized parameters, such as day time, season or species, considering spatial and temporal distribution patterns. These approaches can be generally applied to the situation in Bavaria and be used in a GIS based analysis to explain WVC. 
The analysis of land use as well as land use patterns supports the hypothesis, that land use pattern in general and the dynamics of land use and vegetation in a rural setting could have an influence on animal behaviour and could offer a basis to better explain WVC. This indicates that there is a gap in research, because seasonal and annual changes in land use and vegetation have not been tested so far. Potential explanatory components underpinning the demand to test these hypotheses are the relevance of vegetation as a feedstock for wild animals and the necessity to follow these developments in a changing environment, especially if change occurs on a seasonal as well as an annual basis in a rural and agricultural context. Second can height of vegetation and density and the changes over the seasons influence visibility and hence the ability of drivers to react to the movement of animals in time.

To better understand spatial distribution of WVC also other parameters should be included, that might influence WVC risk. Weather, day time, light conditions are besides vegetation relevant parameters influencing visibility as well as behaviour of drivers and animals. To further develop the idea of risk based management of WVC concepts from big (spatial) data analytics should be tested to consider the number or potential parameters and relevant conditions increasing the risk for WVC.

Critical is the availability of a basic data set for land use and dynamics of vegetation that would allow a more detailed view into the seasonal or better monthly developments on fields and offer the possibility for the analysis of spatio-temporal correlations. While public available land use statistics are only accessible on a municipal level and cannot be used to analyse individual WVC, more detailed information from agricultural statistics are not publicly available due to data privacy concerns. Remote sensing was identified to be the only suitable source of information. Aerial photos where applied in a first experimental approach and indicate dependencies. For a spatial analysis in a next step remote sensed data needs to be analysed to provide a data basis for seasonal vegetation situations and agricultural land use to underpin these first findings through a broader data basis.

Remote sensing data was identified as the only currently open available source for land use data, able to cover seasonal as well as annual changes in land use and vegetation. The methodology proposed to address the "land use" hypothesis foresees an analysis of e.g. Landsat data sets to derive information about land use and vegetation relevant parameters (types of plants, density and coverage) as a spatial time series to identify spatiotemporal correlations with WVC.

Also of relevance seems to be to test a new hypothesis. Relief shape of the region and relief could be factors for habitats of and other landscape structures as well as structural elements and technical infrastructure at and alongside streets could influence animal behaviour and, hence, WVCs.

The results of the project indicate that not only hot spots and areas at risk can be identified, but that further developed tools could be able to forecast changes in these patterns e.g. induced by changes in human activities, and allow the prediction of future WVC hot spots and changes in current patterns due to several influences. These developments could be of relevance to better forecast risks and apply these forecasts to dynamic warning systems and better plan protective measures such as fences, warning signs or reflectors.

It needs to be discussed how all parameters can be used to evaluate risk of WVC and use historic data to forecast areas at risk. Current methodologies do not seem to be ready for this and should be extended by land use pattern as well as weather data.

\section{REFERENCES}

Diaz-Varela, E. R., Vazquez-Gonzalez, I., Marey-Pérez, M. F., \& Álvarez-López, C. J. (2011). Assessing methods of mitigating wildlife-vehicle collisions by accident characterization and spatial analysis. Transportation Research Part D: Transport and Environment, 16(4), 281-287. http://doi.org/10.1016/j.trd.2011.01.002

Dussault, C., Poulin, M., Courtois, R., \& Ouellet, J.-P. (2006). Temporal and spatial distribution of moose-vehicle accidents in the Laurentides Wildlife Reserve, Quebec, Canada. Wildlife Biology, 12(4), 415-425. http://doi.org/10.2981/09096396(2006)12[415:TASDOM]2.0.CO;2

Found, R., \& Boyce, M. S. (2011). Predicting deer-vehicle collisions in an urban area. Journal of Environmental Management, 92(10), 2486-2493. http://doi.org/10.1016/j.jenvman.2011.05.010

Gunson, K. E., Clevenger, A. P., Ford, A. T., Bissonette, J. A., \& Hardy, A. (2009). A Comparison of Data Sets Varying in Spatial Accuracy Used to Predict the Occurrence of WildlifeVehicle Collisions. Environmental Management, 44(2), 268277. http://doi.org/10.1007/s00267-009-9303-y

Hartwig, D. (1993). Auswertung der durch Wild verursachten Verkehrsunfälle nach der Statistik für Nordrhein-Westfalen. Zeitschrift für Jagdwissenschaft, 39(1), 22-33. http://doi.org/10.1007/BF02310214

Hindelang, M., Premo, D., Rogers, E., \& Premo, K. (1999). Addressing deer-vehicle accidents with an ecological landscape GIS approach. In Proceedings of the Third International Conference on Wildlife Ecology and Transportation. FL-ER73-99. Florida Department of Transportation, Tallahassee, Florida (pp. 185-192).

Hubbard, M. W., Danielson, B. J., \& Schmitz, R. A. (2000). Factors Influencing the Location of Deer-Vehicle Accidents in Iowa. The Journal of Wildlife Management, 64(3), 707-713. http://doi.org/10.2307/3802740

Krisp, J. M., \& Durot, S. (2007). Segmentation of lines based on point densities_-An optimisation of wildlife warning sign placement in southern Finland. Accident Analysis \& Prevention, 39(1), 38-46. http://doi.org/10.1016/j.aap.2006.06.002

Morelle, K., Lehaire, F., \& Lejeune, P. (2013). Spatio-temporal patterns of wildlife-vehicle collisions in a region with a high- 
density road network. Nature Conservation, (5). Retrieved from http://orbi.ulg.ac.be/handle/2268/158178

Mysterud, A. (2004). Temporal variation in the number of carkilled red deer Cervus elaphus in Norway. Wildlife Biology, 10(3), 203-211.

Nielsen, C. K., Anderson, R. G., \& Grund, M. D. (2003). Landscape Influences on Deer-Vehicle Accident Areas in an Urban Environment. The Journal of Wildlife Management, 67(1), 46-51. http://doi.org/10.2307/3803060

Putmam, R. J. (1997). Deer and Road Traffic Accidents:

Options for Management. Journal of Environmental

Management, 51(1), 43-57.

http://doi.org/10.1006/jema.1997.0135

\section{ACKNOWLEDGEMENT}

Accident data was provided by the The Bavarian Ministry of the Interior, for Building and Transport - and the Bavarian Police, Geodata from Geobasisdaten Bayern (c) Bayerische Vermessungsverwaltung www.geodaten.Bayern.de

Landsat data. USGS Products - Data available from the U.S. Geological Survey.

Revised June 2015 